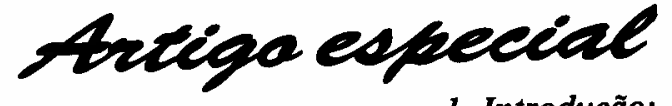

1. Introdução;

2. A diversificação do marketing direto;

3. Relacionamento, a palavra-chave;

4. Dinâmica do marketing com database

5. Suporte à força de vendas;

6. Suporte à força de vendas, uma nova forma de

vender;

7. Benefícios básicos;

8. Manutenção de clientes;

9. Veículos de comunicação e resposta direta; 10. Primeiro, teste, depois teste e continue testando.

\title{
Suporte à força de vendas
}

Eduardo de Souza Aranha

Administrador de empresas pela Escola de Administraçāo de Empresas de Säo Paulo da Fundação Getulio Vargas; pós-graduado em economia e ciências sociais pela Harvard University, EUA.

\section{INTRODUÇÃO}

Estou particularmente feliz por participar dos avanços que estão ocorrendo no campo de marketing direto - desenvolvimentos verdadeiramente revolucionários que estão modificando a face do marketing em todo o mundo.

Posso antecipar que marketing com database não é mais um jargão mercadológico, desses de elevado significado teórico, mas de difícil conversão em termos estratégicos, ou de complexa aplicação prática. Empresas de todos os tipos, nos EUA, na Europa e agora no Brasil, estão incorporando o marketing com database às suas estratégias de marketing. Nos países industrializados, gigantes como IBM, Ford, Xerox, Sears, American Express e milhares de outras grandes, médias e pequenas empresas estão utilizando cada vez mais esse método.

No Brasil a nova ordem econômica alterou substancialmente as condições de mercado, em termos do comportamento do consumidor e da concorrência. Esta nova ordem econômica tem dramatizado a necessidade das empresas de melhorar a eficiência dos seus esforços de marketing.

$\mathrm{Na}$ busca pela eficiência de marketing as empresas tiveram e continuam a ter que ampliar a segmentação de mercado para melhor concentrar os seus esforços. O nível de exatidão de informações sobre os hábitos e o comportamento do consumidor permite infindáveis segmentações do target.

Por outro lado, o rápido crescimento da nossa indústria de informática oferece, em larga escala, eficazes sistemas para construção e administração de databases, a par de crescentes desenvolvimentos tecnológicos na área da comunicação, como o aperfeiçoamento dos serviços do correio e da telefonia. A conjunção desses fatores tem motivado a utilização crescente do marketing direto.

\section{A DIVERSIFICAÇÃO DO MARKETING DIRETO}

Não faz muito tempo que o negócio de marketing direto significava apenas vendas por reembolso postal. $\mathrm{O}$ marketing direto alargou em muito sua abrangência. Empresas-líderes em produtos de consumo, industriais e de serviços, em todo o mundo e agora no Brasil, estão incorporando o marketing direto aos seus esforços, pela simples razão de com ele ganhar eficiência, eficácia e competitividade.

Vamos ver agora como o marketing direto tem contribuído para a maior eficácia empresarial: o marketing direto atua como canal de distribuição, na medida em que ele troca produto por dinheiro. Nesta aplicação, ele está exercendo função típica de um canal de vendas.

Um número crescente de empresas está utilizando o marketing direto para elevar a produtividade da força de vendas. O marketing direto, aplicado à força de vendas, coloca o vendedor numa posição favorável perante o cliente em potencial, já motivado a comprar seu produto. Nesta aplicação, ele já está desempenhando uma preponderante função da administração de vendas.

E muitas empresas estão empregando o marketing direto para elevar o nível de compra de seus clientes, graças a sua alta capacidade de envolvimento e interação direcionada a cada cliente. Nesta aplicação, ele está transformando a fidelidade do consumidor em vendas, dai a atividade estratégica do pós-venda.

O marketing direto também está sendo usado para aumentar a eficácia dos canais de distribuição e desempenhar diversas funções na ativação do marketing mix das empresas.

Marketing direto não pode mais ser considerado o primo pobre do marketing. Sua crescente diversificação o tem colocado em 
novo patamar, distinguindo-o da propaganda, de forma mais clara.

\section{RELACIONAMENTO, A PALAVRA-CHAVE}

O marketing direto não é substituto da propaganda. E nem seu inimigo, o que fica claro, quando entendemos as finalidades da propaganda e do marketing direto.

Embora exista alguma divergência quanto às atribuições da propaganda, há concordância de que sua finalidade básica é a de criar awareness.

Já o marketing direto procura transformar $o$ awareness em relacionamentos constantes. $\mathrm{E}$ vamos estabelecer alguns conceitos básicos para melhor identificar o que seja marketing direto. Um conceito esclarecedor do marketing direto pode ser:

"Marketing direto envia sua mensagem diretamente ao segmento-alvo para produzir uma resposta mensurável e para criar um relacionamento constante."

Embora seja uma conceituação simples, ela permite vislumbrar que marketing direto é um processo de marketing direcionado a estabelecer posteriores relacionamentos entre a empresa e o seu segmento-alvo e vice-versa. É importante ressaltar que este relacionamento é em duplo sentido: da empresa para o segmento-alvo e deste para aquela. E o sucesso dos relacionamentos depende diretamente da qualidade do database.

\section{DINÂMICA DO MARKETING COM $D A T A B A S E$}

Precisamos compreender que database não é uma lista de nomes e endereços com algumas segmentações. Ele é mais, muito mais do que isso; mantém os registros completos do comsumidor e os resultados dos nossos relacionamentos com ele.

Esses registros compreendem:

- Nome, endereço.

- Histórico de compras.

- Comportamento de respostas.
- Perfil demográfico/psicológico.

- Customer service.

- Lucratividade do cliente.

Então o database permite desenvolver esforços de marketing direto para criar e manter relacionamentos com segmentos específicos de mercado, visando a:

- estabelecer seletivamente a base de consumidores;

- intensificar as relações entre a empresa e seus consumidores; - manter a ativação do mercado; - elevar o nível de compras;

- direcionar a compra para os produtos mais rentáveis; - gerar a venda cruzada.

E o mais significativo: existe um processo automático de feedback, pois cada relacionamento alimenta sistematicamente novos registros no database, o que possibilita uma eficácia muito maior, na medida em que podemos definir $e$ identificar segmentos específicos, a partir de dados cada vez mais completos. Aliado a isto, para muitos tipos de negócios, o marketing com database permite à administração de marketing adaptar seus produtos e serviços às características específicas de cada segmento de mercado.

Em última análise, o marketing direto, através desse conjunto de relacionamentos, objetiva gerar uma transação lucrativa com o mercado-alvo, para possibilitar:

- a venda direta;

- ou a visita do vendedor;

- ou para elevar o nível de compras dos nossos clientes atuais.

Vamos ver agora o sistema de suporte à força de vendas.

\section{SUPORTE À FORÇA DE VENDAS}

Se o marketing, como um todo, tem-se desenvolvido muito nos últimos anos, o mesmo não se pode dizer dos sistemas de vendas para o vendedor, quando ele sai a campo. Nesses casos, a venda é feita de maneira tradicional, custosa, e muitas vezes de forma ineficiente. Isto se torna mais dramático quando se avalia $o$ sistema de venda institucional, ou seja, de uma empresa para outra. Isto compreende o processo de vendas de uma indústria de bens de capital para outra indústria, de uma empresa de serviços para outra empresa e até mesmo de uma instituição financeira para pessoas jurídicas. Dentre os inúmeros problemas que poderíamos considerar, no processo de vendas institucional, destacaremos aqueles mais cruciais à maioria das empresas:

5.1 Muito trabalho de prospecção e pouco de negociação

Se você se detiver em analisar as atividades de um vendedor para vender a um novo cliente, inevitavelmente sua conclusão será que ele passa mais tempo prospectando do que vendendo.

Isto porque competem ao vendedor as atividades de localização de clientes potenciais, a identificação de pessoas que decidem a compra e marcar a entrevista com os que decidem. Neste processo que consome boa parte de seu tempo e esforço, o vendedor pode atingir clientes que nunca necessitarão do produto que está sendo oferecido. Tudo isso contribui para o desgaste e diminui a motivação da força de vendas em conquistar novos clientes, ao perceber que suas qualidades e habilidades de negociar passam a ser pouco aproveitadas. É mais difícil ter um cliente potencial à sua frente, do que negociar a venda.

\subsection{Dificuldade de acesso aos escalões que decidem a compra}

Na procura da brecha para efetuar a venda, muitas vezes o vendedor é atendido por pessoas cujo poder decisório é reduzido, fazendo com que ele "pregue no deserto"'. Em outras situações, por não conseguir abordar todas as pessoas que estão envolvidas no processo de compra, a decisão ficará à mercê dos canais internos de comunicação da empresa compradora em potencial. E nós 
sabemos que, na maioria das vezes, eles são ineficientes.

\subsection{Diversidade de comunicação}

É praticamente impossivel um gerente de vendas conseguir que seus vendedores mantenham uniformidade de mensagens $e$ informações sobre o produto a ser vendido. É claro que certa flexibilidade por parte do vendedor é necessária e benéfica. Porém, quando da apresentação do produto ao cliente potencial, é importantíssimo que nenhum dos seus benefícios e principais características sejam esquecidos e que determinada ordem de apresentação dos argumentos seja mantida.

Já se conhece a proverbial dificuldade em se conseguir isso com simples treinamento.

\subsection{Baixa produtividade de vendas}

Até que um vendedor consiga sucesso, muitas e muitas visitas são necessárias. São horas de espera e recusa, além dos altos custos de gasolina, de tempo e, principalmente, de perda de oportunidade de vendas. E quem sabe, depois de todos esses esforços, ele descobre que o limite de crédito, fixado para este novo cliente, é insuficiente para seu objetivo de venda.

Este conjunto de dificuldades pode levar cada vendedor em particular, e a força de venda como um todo, a:

a) dedicar-se apenas a seus clientes atuais, com baixo esforço para conquista de novos clientes;

b) concentrar-se apenas em produtos de demanda garantida ou aqueles que asseguram a çomissão desejada no fim do mês.

$\mathrm{E}$, se essas conseqüências são óbvias, precisamos analisar com mais detalhes o porquê desses comportamentos do vendedor.

Em primeiro lugar, todo vendedor é, antes de tudo, o empresário de si mesmo. Ele sabe que sua remuneração depende de seu volume de vendas, e, normalmente, não se arrisca a conquistar um novo cliente. Prefere dedicar-se a antigos clientes, cujos resultados são mais seguros.

Em segundo lugar, o vendedor é um profissional como qualquer um de nós e, portanto, com necessidades de afirmação e auto-estima, entre outras. Assim, não é todo dia que está disposto a enfrentar seguidos "não" e ver a porta bater a sua frente.

Obviamente, existem os supervendedores que consideram uma negativa como estímulo para fechar a próxima venda. Todavia, tentar montar uma força de vendas baseada em supervendedores é tão inviável como armar um time de futebol com onze jogadores como Pelé.

Qualquer dessas alternativas é prejudicial. Nenhuma empresa aumenta sua lucratividade a longo prazo se não estiver permanentemente conquistando novos clientes. Como também, se a força de vendas não colocar 0 "product mix ótimo de fabricação", a empresa terá rentabilidade sempre abaixo do potencial.

A grande verdade é que $o$ esforço mercadológico das empresas é diariamente prejudicado pela falta de marketing aplicado a vendas, ou pela inexistência de uma tecnologia de vendas.

Em resumo, passou a haver um triplo problema:

- necessidade de aumentar o esforço de vendas;

- escassez de bons profissionais de vendas;

- elevação mais que proporcional das despesas de vendas.

A velha terapêutica de aumentar o percentual de comissões e prêmios não gera mais os mesmos benefícios. $O$ incremento de vendas a curto prazo, em muitos casos, passa a ser acompanhado pela queda da rentabilidade a médio e longo prazos. A situação é nova. $\mathrm{O}$ sistema convencional de vendas apresenta sinais de ineficácia para enfrentar os novos desafios, gerados pela mudança estrutural. E passa a ser mais dramática a necessidade da tecnologia de marketing aplicada a vendas. Mas será ela possível?

6. SUPORTE À FORÇA DE VENDAS, UMA NOVA FORMA $D E$ VENDER

O marketing direto aplicado à força de vendas objetiva, em última análise, aumentar substancialmente a produtividade do vendedor por colocá-lo sempre em posição favorável diante de um cliente potencial, motivado a comprar o seu produto. Esse é o propósito do sistema de marketing direto de suporte à força de vendas.

O que faz o sistema de marketing direto de suporte à força de vendas:

- realiza o trabalho de prospeç̧ão de clientes potenciais;

- identifica e atinge clientes de real potencial;

- o vendedor visita, no cliente, a pessoa-chave;

- facilita o processo de

fechamento de venda;

- controla objetivamente os resultados.

\section{BENEFÍCIOS BÁSICOS}

1. Localiza clientes potenciais por segmento de mercado.

2. Identifica e atinge em cada cliente potencial, as pessoas envolvidas no processo de decisão de compra.

3. Coordena a campanha de atingimento. Cada fase visa derrubar as barreiras existentes ao longo do processo decisório.

4. Equaliza o esforço de atingimento à capacidade de visitas dos vendedores.

5. Coordena as visitas dos vendedores. Coloca-os em posição favorável frente às pessoas que realmente decidem.

6. Atua diretamente nas fases de 
negociação, após a visita. Acelera o fechamento da venda.

7. Programa a força de vendas. Sistema de informação a serviço do vendedor: quem visitar, quem procurar, em que fase se encontra e o que ocorreu anteriormente.

8. Avalia resultados de forma segmentada. Permite projeção de metas em bases realistas e avaliações precisas sobre a produtividade dos vendedores, custos e eficácia de vendas.

9. A administração da empresa acompanha o que está realmente ocorrendo no campo.

Vamos ver alguns casos reais:

BANCO DO CHILE -

Conquistas de novos clientes, pessoas jurídicas.

Problema: o Banco do Chile, o maior banco privado daquele país, estava perdendo participação no mercado de pessoas jurídicas. A causa básica era sua imagem de banco tradicional, rígido e burocrático.

Solução: o Banco do Chile reformulou sua estrutura operacional para pessoas jurídicas e implantou o sistema de marketing direto de suporte à força de vendas dirigido às 300 maiores empresas industriais $\mathrm{e}$ comerciais daquele país.

Resultado: $33 \%$ das empresas atingidas tornaram-se clientes.

\section{JOHNSON \& JOHNSON - fraldas descartáveis}

Problema: conseguir que as principais cadeias de supermercados oferecessem melhor posicionamento e uma seção específica em suas lojas, para as fraldas descartáveis da Johnson \& Johnson. Por ser esse o objetivo de marketing de milhares de produtos, que se utilizam do auto-serviço como canal de distribuição, tornou os supermercadistas insensíveis aos apelos convencionais de venda e promoção.
Solução: foi aplicado o sistema de suporte à força de vendas.

Resultados: foram além das expectativas:

$63 \%$ das lojas atingidas criaram a seção de fraldas descartáveis, aumentaram os espaços nas gôndolas e posicionaram o produto corretamente.

\section{MANUTENÇÃO DE CLIENTES}

Por que as empresas estão investindo cada vez mais na manutenção de seus clientes?

Esta época de dificuldade, caracterizada pelos custos crescentes para o aumento de participação de mercado, tem levado muitas empresas a repensar sobre a validade dos altos custos decorrentes de uma estratégica expansionista. Muitos empresários têm concluído ser altamente saudável deslocar parte ponderável de seus esforços de marketing, para a manutenção de seus atuais clientes.

Enfim, é preciso investir em quem nós já superamos a inércia, em quem acreditou em nossos produtos e serviços, ou seja, naqueles em quem já amortizamos os custos de conversão de clientes potenciais em reais. Em termos estratégicos, reter os clientes pode constituir-se na alternativa mais rentável, quando comparada aos custos da reposição do estoque de clientes.

E dentre as diversas alternativas de marketing e comunicação, 0 marketing direto tem sido altamente eficaz para manutenção do estoque de clientes, porque marketing direto cria forte envolvimento, através do canal permanente de comunicação, entre a empresa e seus clientes.

E o marketing direto vai além. Ele transforma fidelidade em repetição de compras, a níveis crescentes.

\section{VEICULOS DE COMUNICAÇÃO E RESPOSTA DIRETA \\ O importante em tudo isso é ter}

em mente que o marketing direto interage com o mercado-alvo, através de uma forma de comunicação muito própria: a resposta direta.

Resposta direta é a denominação da comunicação do marketing direto. Ela difere da Propaganda Geral por:

- objetivar sempre a obtenção de uma resposta imediata;

- providenciar sempre um veículo para a resposta (cupom ou número de telefone);

- mensurar os resultados.

O importante é salientar que estas três características têm de estar presentes conjuntamente, para se caracterizar a propaganda por resposta direta.

Obter um fluxo detalhado de informações mensuráveis dos esforços de marketing ganha importância estratégica na administração de empresas, hoje, no Brasil.

A informação detalhada do feedback do esforço de marketing tem tanto valor atualmente, quanto um bom controle do fluxo de caixa, ou do nível de produção, ou dos estoques para qualquer empresa.

$\mathrm{E}$ aí reside a grande razão da explosão do marketing direto, o seu processo é totalmente mensurável. Em marketing direto você pode quantificar tudo. $\mathbf{E}$ sempre. Você pode mensurar retorno: meio de comunicação por segmento de mercado, por oferta, por item de produto, por preço; de forma isolada ou combinando estes fatores.

A principal característica do sistema de marketing direto é sua capacidade de medir com precisão o lucro de uma venda ou o custo de uma solicitação de visita, assim como resultado dessa visita.

De fato em marketing direto, nós virtualmente vivemos e morremos para melhorar os resultados.

Assim, marketing direto não é simplesmente um termo sofisticado para mala direta, embora a mala direta seja um de seus meios de comunicação básicos. Ele utiliza qualquer meio de comunicação desde que seja o 
mais indicado para o segmento de mercado desejado.

$O$ marketing direto envolve jornais e revistas. Anúncios com resposta direta estão sendo cada vez mais veiculados entre nós. Pequenos anúncios, grandes anúncios, encartes, todos eles com um objetivo: obter resposta através de um cupom ou telefonema.

Telemarketing é o meio de comunicação cuja utilização mais tem crescido, graças à excepcional capacidade de interação do telefone, facilitando, agilizando e elevando a capacidade de efetuar transações, que é o objetivo do marketing direto.

Televisão é o novo meio de comunicação de marketing direto. É cada vez mais freqüente a veiculação de comerciais mencionando um número de caixa postal ou de telefone.

As empresas que estão usando a estratégia do marketing direto avaliam seus esforços de vendas com total objetividade, porque seus resultados são medidos por. vendas e não só por audiência.

E qual é a principal vantagem de um sistema de marketing totalmente mensurável?

A de minimizar riscos. Com os menores esforços e recursos consegue-se o máximo de resultados. A palavra mágica é teste. Testar é a razão do sucesso em marketing direto.

10. PRIMEIRO, TESTE, DEPOIS TESTE E CONTINUE TESTANDO

Ao avaliarmos o fluxo do sistema de marketing direto, surge a grande pergunta:

" $O$ marketing direto pode ter sucesso, quando operado de forma não-contínua, ou seja, baseado em promoções esporádicas?"

A resposta é: não. Resultados lucrativos e obtenção de volumes crescentes só serão conseguidos através de um esforço contínuo, constante, persistente e repetitivo. Isto porque o importante é a função e não a forma. O objetivo do marketing direto é gerar vendas. Não é relevante no contexto se ele utiliza a forma es meios de propaganda, ou se usa técnica de promoção, ao criar ofertas irresistiveis para vencer a inércia do consumidor.

Se reconhecermos, que o marketing direto exerce a função de vendas, concordaremos, então, que ele deve ser administrado com o mesmo rigor de esforços e avaliações diárias, que desenvolvemos na administração de vendas.

Assim, precisamos sepultar definitivamente a idéia de que o marketing direto pode ser operado lucrativamente, na base das "promoções esporádicas". Afinal, nosso compromisso de vendas mensal e acumulação não pode ficar sujeito ao alto risco de esforços esporádicos. Porque, como em qualquer atividade empresarial, o lucro em marketing direto vem da satisfação contínua, permanente e constante das necessidades do consumidor, que são dinâmicas.

Portanto, o marketing direto deve ser comandado pelo trabalho persistente no desenvolvimento de suas etapas, na avaliação dos seus resultados e, principalmente, na persistência de se encontrar soluções concretas que vençam a inércia do mercado, ao menor custo.

E lógico que só persistência não adianta. Necessitamos também de talento e experiência.

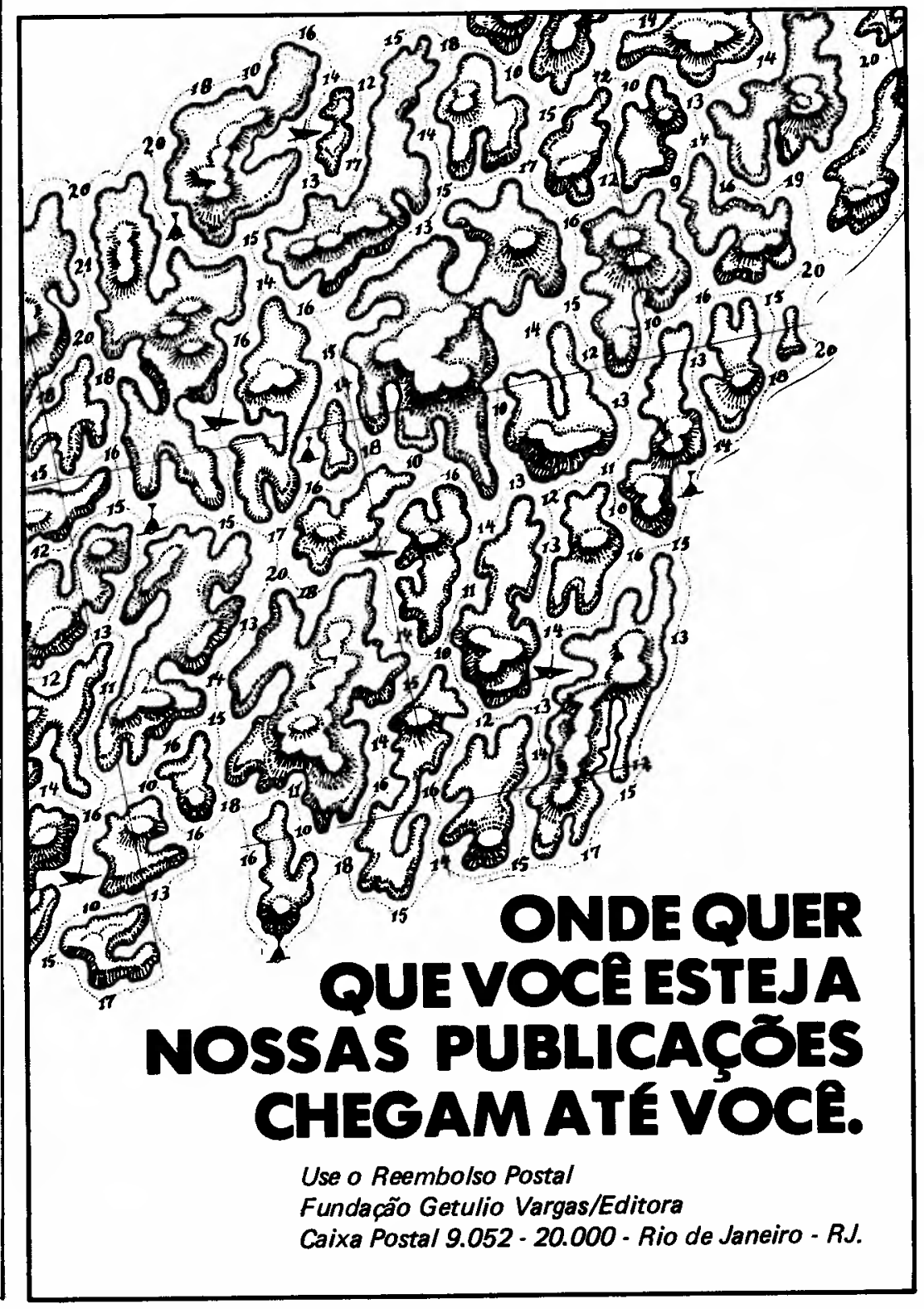

